\title{
Mercury and methylmercury distribution in the intertidal surface sediment of a heavily anthrophogenically impacted saltwater-mangrove-sediment interplay zone
}

\begin{abstract}
Total mercury ( $\mathrm{THg}$ ) and methylmercury $(\mathrm{MeHg})$ concentrations were determined from sediment samples collected from thirty sampling stations in Port Klang, Malaysia. Three stations had $\mathrm{THg}$ concentrations exceeding the threshold effect level of the Florida Department of Environmental Protection and the Canadian interim sediment quality guidelines. $\mathrm{THg}$ and $\mathrm{MeHg}$ concentrations were found to be concentrated in the Lumut Strait where inputs from the two most urbanized rivers in the state converged (i.e. Klang River and Langat River). This suggests that $\mathrm{Hg}$ in the study area likely originated from the catchments of these rivers. MeHg made up 0.06-94.96\% of the sediment's THg. There is significant positive correlation $(\mathrm{p}<0.01)$ between $\mathrm{THg}$ and $\mathrm{MeHg}$ concentrations. Significant positive correlation $(\mathrm{p}<0.05)$ was also observed between fine sediment particles (i.e. clay and silt) with $\mathrm{MeHg}$ concentrations. Sediment particle size, however, was not found to have any influence on $\mathrm{THg}$ concentrations in the sediment in the study area.
\end{abstract}

Keyword: Mercury speciation; Methylmercury; Intertidal surface sediment; Port; Coastal mangrove; Pollution indices 